\title{
Relation Between Clinical Oral Health Status, Oral Health Related Quality of Life, Denture Material Type and Self- perceived General Health, in a General Population
}

\begin{abstract}
ALEXANDRU GRATIAN GRECU ${ }^{1}$, ANDRA ELENA AUNGURENCE I2*, DAN LUCIAN DUMITRASCU³
Iuliu Hatieganu University of Medicine and Pharmacy, Faculty of Dental Medicine, Department of Prosthetic Dentistry and Dental Materials, 8 Victor Babes Str.,400012, Cluj-Napoca, Romania

${ }^{2}$ Grigore T.Popa University of Mediicine and Pharmacy, Faculty of Dental Medicine, 16 Universitatii Str., 700115, Iasi, Romania 3/uliu Hatieganu University of Medicine and Pharmacy, 2nd Medical Department, 8Victor Babes Str.,400012,Cluj-Napoca, Romania

The purpose of the current study was to assess the oral health related quality of life (OHRQoL), general health related quality of life (HRQoL), clinical oral and denture status, as well as their interrelation, within a hospitalized general population. The Romanian versions of the Oral Health Impact Profile-49 (OHIP-49Ro), SF-36questionnaires, together with an additional set of oral health assessment questions, were administered under the interview format to 170 patients, hospitalized in the Second Medical Clinic of Internal Medicine, Cluj-Napoca, Romania. The patients also underwent clinical examination, based on which the DMFT was calculated. Denture status, was as well, registered, together with the denture material. Each patient provided informed consent, prior to any examination. Questionnaire scores were calculated and used for the univariate descriptive statistics, reflecting oral health, OHRQOL and HRQOL sample tendencies. Successively, multiple regression analysis was applied, with the purpose of investigating the relationship between: the clinical oral health status, OHRQOL and HROoL. In the first model, OHROOL, while in the second model the dependent variable was represented by the $H R Q$ oL, each having a set of established predictors. Additionally, for denture wearing patients, OHRQoL variations in respect to the denture material were assessed, using one-way ANOVA. The mean OHIP-49Ro overall score was 31.90. The mean SF-36 subscales score was 60.66. The mean DMFT score was 18.47. For both regression analyses, all the regression models were significant. For the first model, the predictors accounted for $48.5 \%$ of variance in OHRQ oL. For the second model, the highest percent of variance, explained by the predictors, was registered for the Mental Health subscale (22.8\%). DMFT, as a clinical measure, was a statistically significant predictor rather for the perception in general health. However, OHRQoL was a good predictor for HRQoL, as an integrated part of it. Moreover, the oneway ANOVA indicated statistically significant differences in $O H R Q O L$ perception, in respect to the denture material $F(2,82)=3.253, p=0.044$. The current study indicated complex relations between the patients' clinical status, the OHRQOL and HRQoL. The clinical determinants presented direct impact on both OHRQOL and HRQoL. More balanced HRQoL scores suggested that patients focused more on the perception of general health outcomes.
\end{abstract}

Keywords: oral health, HRQoL, denture status

Concepts as Health, Quality of Life and Health Related Quality of Life, have gained, in the last decades, a great importance in regard to the assessment of treatment outcomes and expectations, as well as patients' selfperception [1]. According to the definition given by the World Health Organization, Health is a state of complete physical, mental, and social well-being and notmerely the absence of disease or infirmity [2]. Related to Health, the construct of Quality of Life (QoL) embodies various definitions, due to its ambiguous character [3, 4]. QoL can be defined as concept composed out of both objective (or society-related) and subjective (individual-related) components [5, 6]. Within the concept, influential factors, such as global content with life, income, working place, education, self-perception, overall happiness or emotional welfare, are included [6]. Other definitions refer to theoretical structures such as one's own physical health, social and psychological wellbeing, proper functioning and personal beliefs. The degree of adaptation, self-control, selfesteem, positive or negative visions about life, life expectancy or social standards also contribute in defining QoL $[7,8]$.
Health Related Quality of Life (HRQoL) presents the same character of multidimensionality, as the QoL, targeting multiple aspects of an individual's daily living: psychological, emotional, physical or social $[9,10]$. It can be defined as a relation between complete health, selfperception of actual or potential health, and disability. QoL is usually seen as a broader term; HRQ oL targets only the branches of QoL, which are influenced by health (clinical and behavioral influences) [8].

The term Oral Health Related Quality of Life (OHRQoL) can be considered a subdivision of HRQoL[11], and it is meant to explain the way in which oral conditions determine the daily life of a patient. This concept is as well multidimensional [12], encompassing one's subjective perceptions in respect to the own oral health, proper functioning, emotional welfare, treatment outcome predictions and content, survival, proper functioning, absence of pain, together with the sense of self. OHRQoL has broad utilizations in survey-design studies, as well as in clinical research. OHRQoL has been appointed by the World Health Organization (WHO) as a valuable division of the Global Oral Health Program $(2003)[13,14]$. Both the 
HRQoL and OHRQoL are measurable through specific selfreport questionnaires [4]. In respect to HRQ oL, one of the most widely used instruments, is represented by the Medical Outcome Study Short Form 36-item (SF-36) [15, 16]; SF-36 has been applied with the purpose to identify impacts of various general conditions upon the HRQoL [1719]. OHRQoL is, as well, measured through questionnaires [12]. The measurement of both HRQOL and OHRQoL has become an indispensable component of health and oral health surveys or clinical studies, rendering a precise evaluation of the therapeutic outcomes [20]. Multiple questionnaires were developed, for the operationalization of the OHRQ oL construct [21], the most widely used being the Oral Health Impact Profile [22], both in its long [23] and short form[24].

The relation between the HRQOL and OHRQOL has been investigated in various studies, targeting both general condition patients, as well as patients with oral pathology, using different protocols and questionnaires. General conditions related to oral health, accordingly to the literature, include: rheumatoid arthritis $[25,26]$, multiple sclerosis [27, 28], stroke [29], coronary heart disease [30] or hepatitis C [31, 32]. Additional findings suggest that hospitalized patients might: lack awareness regarding their own oral health [26[, suffer from social handicapping [26], have reduced oral and dental self-care possibilities or lack proper oral hygiene ]33].

OHRQoL has been, as well, related to the nature of the dental treatment [34], including the type of the used restorative material [35]. The fabrication of both fixed and removable dentures implies the usage of various materials. In respect to the fixed dentures, single-tooth crowns or partially fixed dentures currently benefitfrom the properties of dental ceramics, in both their porcelain fused to metal and, more often, full ceramic version [36, 37]. Full ceramic systems are constantly evolving, with the purpose of providing enhanced combined strength and optical properties, in either heat-pressed [38] or milled forms [39]. The degree in which a ceramic material can influence one's self-perception in respect to the quality of life, is, though debatable within the literature [40]. Materials used in the construction of removable partial dentures present, as well, advantages and disadvantages, regarding mechanical properties [41] or the interface with oral tissues [42]. Moreover, the impact of removable dentures upon the patients' OHRQoL has been researched [43], showing that the denture material type and quality can influence the OHRQOL [44].

The aim of the current study is to assess the OHRQoL as an integrated part of the HRQoL, the clinical status and prosthodontics status in an internal medicine hospitalized patient population. More specifically, the research objectives are:

(i) to assess the HRQoL of a hospitalized Romanian patient population;

(ii) to evaluate the oral health status and to assess the OHRQoL of the same population;

(iii) to evaluate the denture status and degree of content regarding the dentures, in the same population;

(iv) to observe the relation between oro-dental clinical parameters, OHRQoL and HRQoL;

(v) to observe the relation between the denture material type and the OHRQOL.

The following hypotheses were formulated:

a. Patients with lower oral health status parameters will report a significantly lower OHRQoL;

b. OHRQoL can significantly be predicted by clinical parameters and basic oral health self-perception; c. HRQOL can significantly be predicted by OHRQoL;

$d$. The denture status and the denture materials have significant influence upon the patients' OHRQoL.

\section{Experimental part}

Materials and method

Instruments

Self-reported measures

1) The Oral Health Impact Profile-49: the Oral Health Impact Profile-49 (OHIP-49) is a complex questionnaire, used in the assessment of patients OHRQoL. Based on the Locker's Model of Oral Health [45], OHIP-49 presents established good psychometric properties, and is widescale used. OHIP exists in various forms, developed from the original version, according to specific patient needs: a short form (OHIP-14) [24], a version for temporomandibular pathology assessment [46] or a pediatric version [47]. The long form, as well as the short form has been favorably applied in clinical studies, assessing specific psychological, social or functional effects of different orodental conditions. OHIP-49 has been translated and validated for distinct languages and cultures [48-50].

OHIP-49's original version includes 49 items, organized in seven subscales (conceptual dimensions): functional limitation, physical pain, psychological discomfort, physical disability, psychological disability, social disability and handicap [51]. The interviewed subjects are asked to report how often a specific impact has been experienced during the last 12 months. Answers are structured on a five-point Likert-scale, with numeral encryption: never $(0)$, hardly ever (1), occasionally (2), fairly often (3) and very often (4). Furthermore, a Don't know judgment option has been incorporated. Blank entries, together with Don't know marked responses, are encoded as missing values.

In agreement with the directions of Slade, the questionnaire is discarded, if nine or more responses are left uncompleted or evaluated with the Don't know answering option. Within the present study, there was no discarded questionnaire, in respect to this rule. Missing answers $(<1 \%)$ were imputed using item mean imputation. Scores were calculated through summing up the item scores, respecting the interval 0-4, for each respondent, within each subscale. Overall OHIP-49Ro scores were likewise calculated. Regarding the study sample, the mean values were computed for each of the seven subscales. Higher scores indicate the perception of a poorer OHRQoL. Item weights were not applied, because their usage is arguable, within the literature $[48,52]$. The validated Romanian version of OHIP-49 (OHIP-49Ro) was applied in the current study [53].

2) Medical Outcomes Study 36-Item Short Form Survey (RAND 36-Item Health Survey), most often abbreviated as MOS SF-36, is a HRQoL and general health assessment questionnaire. Developed by Ware and Sherbourne (1992) [15], the index was derived from more extended instruments, applied on patients involved within the Medical Outcomes Study (MOS), a complex evaluating study of both the disease effects on the patient's quality of life and the practitioner treatment methods, in distinct medical care environments. SF-36's structure comprises 36 questions, organized in eight general health concepts: physical functioning, bodily pain, role limitations due to physical health problems, role limitations due to personal or emotional problems, general mental health, social functioning, energy/fatigue, and general health perceptions. Additionally, a single item, indicating the self-perceived health-transformation, has been included (incorporated) $[15,16]$. Scores for SF-36 were computed accordingly to 
the user's manual, individually for each subscale, by calculating the raw subscale scores and transforming each of them to a scale, ranging from 0 to 100 [16]. Higher SF36 scores indicated, thus, the perception of an improved HRQoL.

3) A set of 9 questions, addressing the following issues: perceived global oral health, denture selef-assessment, perceived oral discomfort and perceived parafunctions:

A perceived global oral health evaluation question: How would you rate the health status of your mouth? (Answering options: excellent, very good, good, decent, bad).

Denture self-assessment questions: 1. Do you have in your mouth: natural teeth, a removable denture of a complete denture? (YES/NO answers for each); 2. Are your dentures in a good state?

Perceived oral discomfort assessment questions: 1 . Have you felt burn symptoms in your mouth?; 2. Have you felt pain or specific sounds in your temporomandibular joint?; 3. Have you encountered difficulties/pain when opening the mouth?(YES/NO answers answer for all three questions).

Parafunctional behavior assessment questions: 1 . Do you have the habit of grinding your teeth?2. Do you usually bite your nails?; 3. Do you usually introduce your tongue, lips, cheeks or other objects between your teeth?(YES/NO answers answer for all three questions).

\section{Objective oral health evaluation measures}

The DMFT (Decayed, Missing, Filling-Teeth) index, described by Klein [54], has been applied, as an objective rating of the sample's oral health status. DMFT is described by the WHO as a diagnostic index for decayed, missing and filled teeth or teeth surfaces. The DMFT scores range from 0 to 32 and are subject to normative data [55]. DMFT has been applied using the WHO administering procedures [55]. Additionally, for the denture wearing patients, the quality of the dentures, as well as the manufacturing material were clinically assessed, through inspection and probing; the investigated parameters referred to the presence of coloration, dental morphology, contact points and material degree of wear. The material impact on the soft parts was as well evaluated, by investigating the presence of denture material-related mucosal lesions.

\section{Participants}

The sample represented a convenience sample and included 170 patients, hospitalized in the Second Medical Clinic of Internal Medicine, Cluj-Napoca, Romania. The sample was defined by the subsequent characteristics: gender: $60 \% \mathrm{~F}, 40 \% \mathrm{M}$; age: $18-89$ years, education level varying from middle school to college (Table 1 ).

\section{Method}

The current study was devised as a cross-sectional survey. The Ethics Committee of the Iuliu Hapieganu University of Medicine and Pharmacy, Cluj-Napoca granted the agreement for the study. A form, presenting the objectives of the study, as well as the patients' rights, was read to each subject. Each responding subject supplied an informed consent.

The three above presented questionnaires were applied within one session. The interview layout was chosen, in order to minimize the rate of unanswered items (51). Each item and response option was read loudly for every patient, by four formerly calibrated interviewers, which also recorded the answering ratings of the subjects. The DMFT index was, as well, applied for each patient. The hospitalized patients were examined at the bedside, using an examination tray containing sterile oral mirror, dental explorer and tweezers. Examinations were executed under aseptic conditions. Subjects were individually evaluated, in their own patient room, during a single interview session. The mean time span for one interview and examination session was 15 minutes, with a variation of 5 minutes.

\section{Data analysis}

Univariate descriptive statistics (mean, standard deviation and standard error) was used in order to evaluate the sample's characteristics regarding oral health, OHRQOL and HRQoL scores. Successively, multiple regression analysis was applied, with the purpose of investigating the relationship between: i) the oral health status, basic oral health perception and OHRQoL; and, ii) clinical and self-reported measures of OHRQ oL on HRQOL. Multiple regression models are used in literature in order to investigate complex relationships between a set of predictor variables and dependent variables [33, 56].

Thus, for the first model, OHRQoL was chosen as dependent variable (and was represented by the OHIP49Ro subscale and overall scores), having as predictors a basic oral health self perception measure (represented by the scored of the perceived global oral health evaluation question, denture self-assessment questions, perceived oral discomfort assessment questions and parafunctional behavior assessment questions) and the assessed clinical dental status of the subjects (represented by the DMFT scores).

For the second model, the dependent variable was represented by the HRQOL (represented by the SF-36 subscale scores), having as predictors a basic oral health self-perception measure (composed by the same scores as in the first model), the assessed clinical dental status of the subjects (DMFT scores) and the OHRQoL measure (represented by the overall and subscale OHIP-49Ro scores).

The models are described in detail in the discussion section, together with their significance.

Additionally, the following inferential statistical procedures were applied, in order to investigate the relationship between denture type, denture material and the perception of OHRQOL:

- the t-test, with the purpose of investigating differences in the OHIP-49Ro subscale/overall scores and oral health perception scores, between patients presenting fixed or removable dentures and those presenting none;

- the chi-squared test, in order to assess the differences between patients presenting fixed or removable dentures and those presenting none, in respect to the burn symptoms, teeth grinding, nails biting and object interposing assessment questions;

- two-way analysis of variance (ANOVA), in order to investigate whether there is an interaction effect between the presence of dentures and gender on oral health selfperception; the presence or absence of dentures and gender were selected as independent variables, while oral health self-perception as dependent variable, expressed through the OHIP-49Ro subscale/overall scores and the oral health self-assessment question scores;

- one-way ANOVA, with the purpose of evaluating possible OHRQoL differences between patients presenting partially fixed dentures manufactured from different materials.

These statistical procedures were employed in order to highlight the impact of an artificial material, within the oral cavity, as perceived by the patients, together with the 
patients' degree of satisfaction in respect to a specific denture material.

The study also investigated correlations between the OHIP-49Ro scores, the SF-36 scores, the DMFT scores and age and education.

All statistical analyses were performed using the IBM SPSS version 23 software (57). Results were considered significant at a critical threshold, á=0.05.

\section{Results and discussions}

\section{Descriptive statistics}

The distribution of the sample, in respect to gender, age and education, can be assessed in Table 1.

Regarding the dental characteristics of the sample, $11.2 \%$ of the patients presented a bimaxillary complete edentulous state (Table 2).

Out of the dentate patients ( $88.8 \%$ ), the highest percent (41.2\%) presented between 16 and 24 teeth, only $5.89 \%$ presenting more than 24 teeth. $72.4 \%$ of the patients were able to self-approximate the number of the own present teeth.

The mean DMFT score for the sample was 18.47. The highest DMFT scores were obtained for the bimaxillary complete edentulous patients (DMFT $=32$, for $11.17 \%$ of the sample); $53.52 \%$ of the sample presented DMFT values over 16; patients between 18-34 years (18.23\%) presented an average DMFT score of 11.12, patients between 35-44 years (6.47\%) presented an average DMFT score of 15.36 , patients between $45-65$ years $(51.76 \%)$ presented an average DMFT score of 18.17, while patients above 65 years (23.52\%) had an average DMFT of 25.67 .

The frequency of fixed or removable denture wearing, together with the distribution of the fixed partial denture material, can be assessed in Table 2. Respond frequencies for the self-reported oral health assessment questions can be found in Table 3. The highest percent of subjects (32.9\%) rated their own oral health as good. $88 \%$ of the denture wearers were not satisfied by the quality of their dentures. The percent of subjects, which reported no oral discomfort or parafunctions, prevailed, for each of the six questions (Table 3).

Mean scores for the computed oral health self-perception question groups can be assessed in table 4 .

The OHIP-49Ro mean subscale scores and the OHIP49 Ro overall sample score are presented in table 5.

The SF-36 subscale scores are presented in table 6.

\section{Multiple linear regression analysis}

Multiple linear regression analysis was used in order to investigate if the OHRQoL (represented by the OHIP-49Ro overall scores, as well as the OHIP-49Ro subscale scores) is predicted by the DMFT scores, denture status and oral

\begin{tabular}{|c|c|c|c|}
\hline Sociodemographic variables & $\begin{array}{l}\text { Number of } \\
\text { subjects }\end{array}$ & Frequency (\%) & Mean(SD) \\
\hline \multicolumn{4}{|l|}{ Gender } \\
\hline Female & 69 & 40.6 & \\
\hline Male-- & 101 & 59.4 & \\
\hline Age (years) & 170 & & $53.05(16.16)$ \\
\hline \multicolumn{4}{|l|}{ Educational level } \\
\hline Middle School & 38 & $22.4^{-}$ & \\
\hline High school & 91 & 51.2 & \\
\hline Bachelor degree & 37 & 21.8 & \\
\hline Master degree & $7^{--}$ & 4.1 & \\
\hline Ph.D. & 1 & $.6^{--}$ & \\
\hline
\end{tabular}

Table 1

DEMOGRAPHIC CHARACTERISTICS OF THE SAMPLE $(n=170)$

\begin{tabular}{|c|c|c|c|c|}
\hline & Number of subjects & Frequency (\%) & Meant/-SD & \\
\hline \multicolumn{5}{|l|}{ Dental status } \\
\hline Assessed number of teeth & & & $13.6(8.1)$ & \multirow{26}{*}{$\begin{array}{c}\text { Table } 2 \\
\text { DENTAL CHARACTERISTICS AND } \\
\text { PROSTHODONTIC STATUS OF } \\
\text { THE SAMPLE }(\mathrm{N}=170)\end{array}$} \\
\hline $0^{--10}$ & 19 & 11.2 & & \\
\hline $1-8$ & 29 & 17 & & \\
\hline $9-15$ & 42 & 24.7 & & \\
\hline $16-24$ & 70 & 41.2 & & \\
\hline$>24$ & 10 & 5.89 & & \\
\hline \multicolumn{4}{|l|}{ Self-reported number of teeth } & \\
\hline Answered & 123 & $72.4^{-}$ & $14.26(10.85)$ & \\
\hline Don't know & $47^{--}$ & 27.6 & & \\
\hline DMFT score & & & $18.47(8.05)$ & \\
\hline Decayed & & & $1.85(3.18)$ & \\
\hline Missing & & & $15.37(9.94)$ & \\
\hline Filled & & & $1.28(2.66)$ & \\
\hline \multicolumn{4}{|l|}{ Prosthodontic status } & \\
\hline No fixed or removable denture & 68 & $40^{---}$ & & \\
\hline Only fixed partial denture & 67 & 39.4 & & \\
\hline Only partial removable denture & 15 & 8.82 & & \\
\hline Only complete denture & 26 & 15.29 & & \\
\hline $\begin{array}{l}\text { Both bridge and partial removable } \\
\text { denture }\end{array}$ & 7 & 4.11 & & \\
\hline $\begin{array}{l}\text { Both partial removable and complete } \\
\text { denture }\end{array}$ & 5 & $2.94^{-}$ & & \\
\hline Both bridge and complete denture & 5 & 2.94 & & \\
\hline Bridge, removable and complete denture & 4 & 2.35 & & \\
\hline \multicolumn{4}{|l|}{ Fixed partial denture material type } & \\
\hline Metal $^{2}$ & 29 & 17.05 & & \\
\hline Metal-acrylic & 35 & 20.58 & & \\
\hline Porcelain-fused-to-metal & 21 & 12.35 & & \\
\hline
\end{tabular}




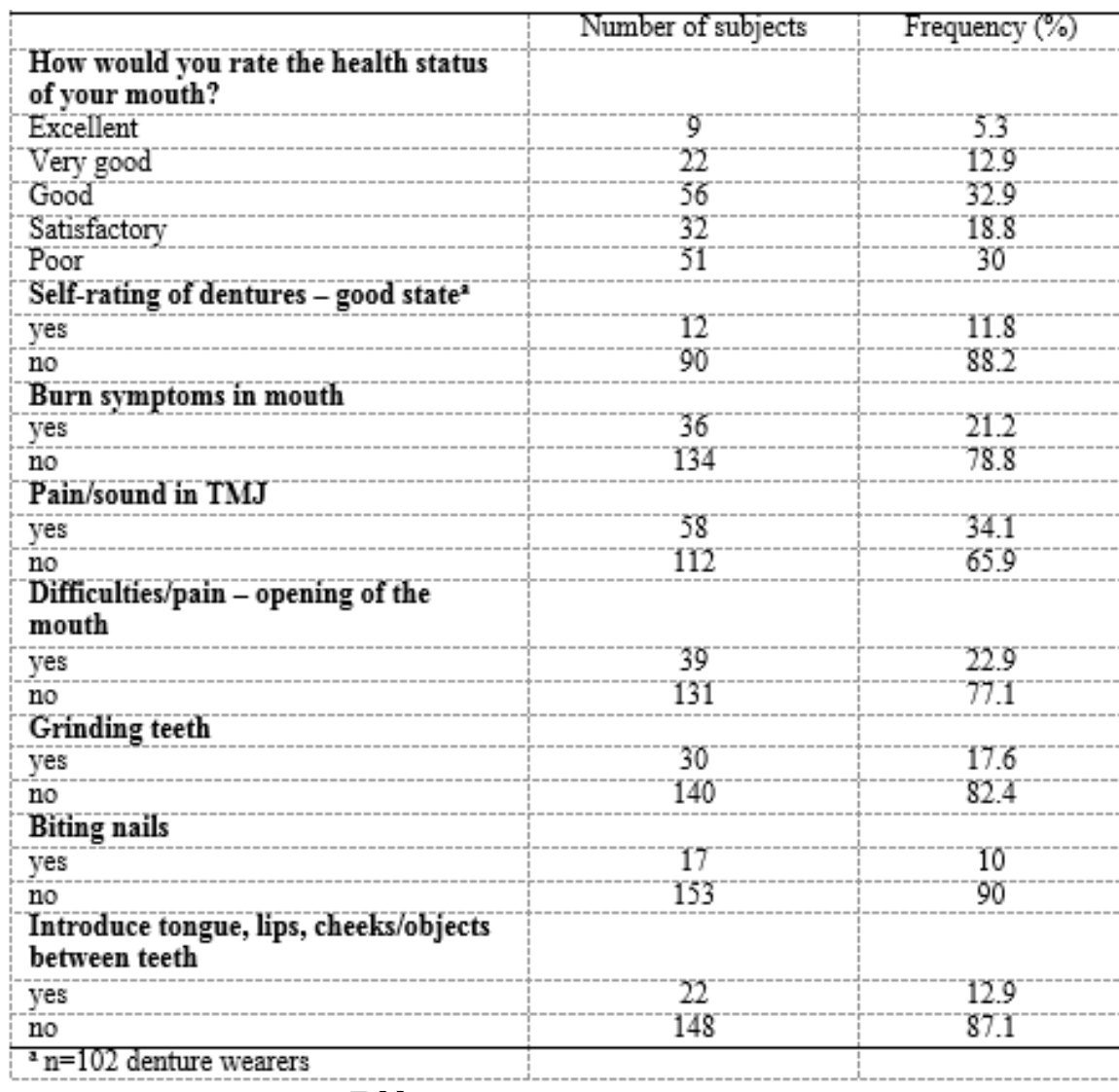

Table 4

SELF-PERCEPTION QUESTION CATEGORIES SCORES ( $\mathrm{N}=170)$

\begin{tabular}{|l|c|}
\hline & Mean+/-SD \\
\hline Prosthodontic status & $.40(.77)^{-}$ \\
\hline Oral pain burm & $.78(1)^{-}$ \\
\hline Parafunctions & $1.7(82)^{-1}$ \\
\hline
\end{tabular}

Table 5

OHIP-49RO SUBSCALE SCORES AND OVERALL SCORE $(n=170)$

\begin{tabular}{|l|c|}
\hline & Meant/SD \\
\hline Functional Limitation & $8.24(5.88)$ \\
\hline Physical Pain & $6.90(6.45)$ \\
\hline Psychological Discomfort & $4.99(5.85)$ \\
\hline Physical Disability & $5.65(6.49)$ \\
\hline Psychological Disability & $2.99(4.67)$ \\
\hline Social Disability & $1.45(3.34)$ \\
\hline Handicap & $1.68(3.53)$ \\
\hline Overall OHIP Score & $31.90(29.93)^{-1.59}$ \\
\hline
\end{tabular}

\begin{tabular}{|c|c|c|c|c|c|}
\hline & $\mathbf{R}$ & R square & $\mathrm{F}$ & df & Sig. \\
\hline OHIP overall score & 0.696 & 0.485 & 30.849 & $(5,164)$ & 0.000 \\
\hline \multicolumn{6}{|l|}{ OHIP-49Ro Subscales } \\
\hline Functional Limitation & 0.683 & 0.466 & 28.661 & $(5,164)$ & 0.000 \\
\hline Pain & 0.636 & 0.404 & 22221 & $(5,164)$ & 0.000 \\
\hline Psychical Discomfort & 0.612 & 0.374 & 19.606 & $(5,164)$ & 0.000 \\
\hline Physical Disability & 0.660 & 0.436 & 25.349 & $(5,164)$ & 0.000 \\
\hline Psychical Disability & 0.511 & 0.261 & 11.584 & $(5,164)$ & 0.000 \\
\hline Social Disability & 0.413 & 0.171 & 6.745 & $(5,164)$ & 0.000 \\
\hline Handicap & 0.487 & 0.237 & 10.118 & $(5,164)$ & 0.000 \\
\hline
\end{tabular}

Table 3

SELF-REPORTED ORAL HEALTH ASSESSMENT QUESTIONS $(\mathrm{N}=170)$
Table 6

SF-36 SUBSCALE SCORES AND HEALTH-TRANSFORMATION SCORE $(n=170)$

\begin{tabular}{|l|c|}
\hline & Mean+/-SD \\
\hline Physical functioning & $76.91(28.63)$ \\
\hline $\begin{array}{l}\text { Bodily pain } \\
\text { Role limitations due to } \\
\text { physical health problems }\end{array}$ & $50.00(48.19)$ \\
\hline $\begin{array}{l}\text { Role limitations due to } \\
\text { personal or emotional } \\
\text { problems }\end{array}$ & $61.61(18.06)$ \\
\hline General mental health & $51.52(33.66)$ \\
\hline $\begin{array}{l}\text { Social functioning } \\
\text { Energy fatigue }\end{array}$ & $63.17(23.13)$ \\
\hline \begin{tabular}{l} 
General health perceptions \\
\hline $\begin{array}{l}\text { Self-perceived health- } \\
\text { transformation }\end{array}$
\end{tabular} & $64.11(46.57)$ \\
\hline
\end{tabular}

Table 7

MULTIPLE LINEAR REGRESSION ANALYSIS FOR THE FIRST TESTED MODEL health self-perception questions. F, R square and significance of the analysis are presented in table 7.

Standardized ( $\beta$ ), unstandardized (B) coefficients and their significance (significance level $p<0.05$ ) are presented in table 8.

Multiple linear regression analysis was, as well, employed, in order to investigate if the HRQoL (represented by the SF-36 subscale scores) is predicted by the DMFT scores, denture status self-perception questions, oral health self-perception questions and the overall OHIP-49Ro scores. F, R square and significance of the analysis are presented in table 9.
Standardized $(\beta)$, unstandardized $(B)$ coefficients and their significance (significance level $p<0.05$ ) are presented in table 10.

\section{Inferential statistics}

The t-test did not indicate any statistically significant differences in respect to the OHIP-49Ro subscale/total scores, between denture wearing and denture nonwearing patients $(p>0.05)$;

The chi-square test did not indicate any statistically significant differences between denture wearing and denture non-wearing patients, in respect to the burn 
Table 8

MULTIPLE LINEAR REGRESSION ANALYSIS FOR THE SECOND TESTED MODEL

\begin{tabular}{|c|c|c|c|c|c|c|}
\hline & & \multicolumn{5}{|c|}{ Predictors } \\
\hline & & $\begin{array}{l}\text { DMFT overall } \\
\text { score }\end{array}$ & $\begin{array}{l}\text { Global OH self- } \\
\text { perception }\end{array}$ & $\begin{array}{c}\text { Denture } \\
\text { assessment }\end{array}$ & $\begin{array}{l}\text { Assessment of } \\
\text { para-functions }\end{array}$ & $\begin{array}{l}\text { Assessment of } \\
\text { oral discomfort }\end{array}$ \\
\hline \multirow{3}{*}{$\begin{array}{l}\text { OHIP overall } \\
\text { score }\end{array}$} & $B$ & 0.005 & 0.328 & -0.008 & 0.085 & 0.124 \\
\hline & $\beta$ & 0.066 & 0.600 & -0.027 & 0.101 & 0.191 \\
\hline & Sig. & 0.271 & $0.000 *$ & 0.639 & 0.087 & $0.00 \mathrm{l}^{*}$ \\
\hline \multicolumn{7}{|l|}{$\begin{array}{l}\text { OHIP-49Ro } \\
\text { Subscales }\end{array}$} \\
\hline \multirow{3}{*}{$\begin{array}{l}\text { Functional } \\
\text { Limitation }\end{array}$} & $B$ & 0.002 & .368 & -0.015 & 0.145 & 0.139 \\
\hline & $\beta$ & 0.021 & .587 & -0.041 & 0.149 & 0.187 \\
\hline & Sig. & 0.726 & $.000^{*}$ & 0.471 & $0.013 *$ & $0.002^{*}$ \\
\hline \multirow[t]{3}{*}{ Pain } & $B$ & -0.007 & .329 & -0.001 & $0.170^{\circ}$ & 0.245 \\
\hline & $\bar{\beta}$ & -0.072 & .474 & -0.003 & 0.158 & 0.297 \\
\hline & Sig. & 0.265 & $.000^{*}$ & 0.956 & $.013^{*}$ & $.000 \%$ \\
\hline \multirow{3}{*}{$\begin{array}{l}\text { Psychical } \\
\text { Discomfort }\end{array}$} & $B$ & 0.011 & .582 & -0.030 & 0.046 & -0.011 \\
\hline & $\beta$ & 0.073 & .592 & -0.053 & $0.031^{-}$ & -0.009 \\
\hline & Sig. & 0.270 & $.000 *$ & 0.393 & 0.635 & 0.882 \\
\hline \multirow{3}{*}{$\begin{array}{l}\text { Physical } \\
\text { Disability }\end{array}$} & $B$ & 0.020 & .345 & -0.004 & 0.085 & 0.143 \\
\hline & $\beta$ & 0.201 & .513 & -0.011 & 0.081 & 0.179 \\
\hline & Sig. & $0.002 *$ & $.000^{*}$ & 0.852 & 0.185 & $0.004^{-2}$ \\
\hline \multirow{3}{*}{$\begin{array}{l}\text { Psychical } \\
\text { Disability }\end{array}$} & $\bar{B}$ & 0.005 & .301 & -0.021 & -0.033 & 0.087 \\
\hline & $\beta$ & 0.051 & .463 & -0.057 & $0-.032$ & 0.113 \\
\hline & Sig. & 0.476 & $.000^{*}$ & 0.400 & 0.643 & 0.106 \\
\hline \multirow{3}{*}{$\begin{array}{l}\text { Social } \\
\text { Disability }\end{array}$} & $B$ & 0.005 & 184 & 0.015 & 0.057 & 0.086 \\
\hline & $\beta$ & 0.064 & 330 & 0.048 & 0.067 & 0.129 \\
\hline & Sig. & 0.399 & $.000^{*}$ & 0.499 & 0.371 & 0.081 \\
\hline \multirow[t]{3}{*}{ Handicap } & $B$ & 0.006 & 188 & -0.017 & 0.056 & 0.104 \\
\hline & $\bar{\beta}$ & 0.077 & .382 & -0.062 & 0.074 & 0.178 \\
\hline & Sig. & 0.291 & $.000^{*}$ & 0.369 & 0.299 & $0.013^{-}$ \\
\hline
\end{tabular}

B, - B, Sig. - probability estimated based on $\mathrm{HO}$.

\begin{tabular}{|l|c|c|c|c|c|}
\hline & R & R square & F & df & Sig. \\
\hline SF-36 Subscales & & & & & \\
\hline Physical Functioning & 0.388 & 0.151 & 5.812 & $(5,164)$ & 0.000 \\
\hline Physical Role & 0.351 & 0.123 & 4.618 & $(5,164)$ & 0.001 \\
\hline Bodily Pain & 0.297 & 0.088 & 3.179 & $(5,164)$ & 0.009 \\
\hline General Health & 0.273 & 0.074 & 2.638 & $(5,164)$ & 0.025 \\
\hline Vitality & 0.392 & 0.154 & 5.958 & $(5,164)$ & 0.000 \\
\hline Social Functioning & 0.288 & 0.083 & 2.960 & $(5,164)$ & 0.014 \\
\hline Emotional Role & 0.363 & 0.132 & 4.967 & $(5,164)$ & 0.000 \\
\hline Mental Health & 0.478 & 0.228 & 9.690 & $(5,164)$ & 0.000 \\
\hline Health Transition & 0.258 & 0.097 & 2.345 & $(5,164)$ & 0.044 \\
\hline
\end{tabular}

Table 9

STANDARDIZED ( $\beta$ ), UNSTANDARDIZED (B) COEFFICIENTS AND THEIR SIGNIFICANCE FOR THE FIRST TESTED MODEL symptoms, teeth grinding, nails biting and object interposing assessment questions.

The two-way ANOVA was conducted in order to examine the effect of the denture presence and gender on oral health self-perception. The two-way ANOVA indicated statistically significant differences between the denture wearing patients and the denture non wearing ones, for the handicap subscale scores, $F(1,166)=4.034, p=0.046$. For the other subscales, and the overall OHIP-49Ro scores, the two-way ANOVA did not indicate any statistical significant effects $(p>0.05)$.

The one-way ANOVA was conducted in order to examine differences in oral health self-perception, between the patients presenting dentures from different material types: complete metal, metal-acrylic and porcelain-fused-to-metal fixed partial dentures. The oneway ANOVA indicated statistically significant differences, between the patients presenting dentures from different materials, in respect to the oral-health self-assessment question scores, $F(2,82)=3.253, p=0.044$. The Post Hoc Least Significant Difference test indicated that the scores of the patients presenting porcelain-fused-to-metal dentures were statistically significantly lower compared to the scores of the patients presenting complete metallic dentures, $p=0.047$; moreover Post Hoc Least Significant Difference test indicated that the scores of the patients presenting porcelain-fused-to-metal dentures were statistically significantly lower compared to the scores of the patients presenting metal-acrylic dentures, $p=0.016$. Thus, the patients presenting porcelain-fused-to-metal dentures reported an enhanced OHRQoL. 36 scores, DMFT scores and age, education were evaluated. The following statistically significant correlations were obtained:

-between scores of the OHIP-49Ro Physical Disability subscale and age $(r=0.225, p=0.003, p<0.01)$; the overall DMFT score and age ( $r=0.606, p=0.001)$; the DMFT score and education $(r=-0.428, p=0.001, p<0.01)$; the DMFT score and OHIP-49 overall mean score $(r=0.207, p=$ 0.007)

-between age and the scores of the following dimensions of SF-36: Physical Functioning $(r=-0.454, p=0.001$, $p<0.01)$, Physical Role $(r=-0.367, p=0.001, p<0.01)$, Bodily Pain $(r=-0.232, p=0.02)$, Vitality $(r=-0.326, p=$ $0.001, p<0.01)$, Emotional Role $(r=-0.209, p=0.06$, $p<0.01)$, Mental Health $(r=-0.244, p=0.01)$, Health Transition $(r=0.215, p=0.05, p<0.01)$.

The purpose of the current study was to assess the OHRQOL, HRQOL and the relationship between them, in a hospitalized Romanian patient sample. In respect to the single oral health self-assessment question, $32.9 \%$ of the sample's patients self-rated rated their oral health as good, while $30 \%$ of the patients perceived their oral health as poor. Moreover, oral discomfort and parafunctions assessment questions registered mostly negative answers in more than $70 \%$ of the sample (Table 3 ).

The highest OHIP-49 Ro mean subscale scores were obtained within the subscales of Functional Limitation, Psychological Discomfort, followed by Physical Pain, with the overall mean OHIP-49Ro score being is in accordance 


\begin{tabular}{|c|c|c|c|c|c|c|}
\hline & & \multicolumn{5}{|c|}{ Predictors } \\
\hline & & $\begin{array}{l}\text { DMFT overall } \\
\text { score }\end{array}$ & $\begin{array}{l}\text { Denture } \\
\text { assessment }\end{array}$ & $\begin{array}{l}\text { Assessment of } \\
\text { para-functions }\end{array}$ & $\begin{array}{l}\text { Assessment of } \\
\text { oral discomfort }\end{array}$ & $\begin{array}{l}\text { OHIP overall } \\
\text { score }\end{array}$ \\
\hline \multicolumn{7}{|l|}{$\begin{array}{l}\text { SF-36 } \\
\text { Subscales }\end{array}$} \\
\hline \multirow{3}{*}{$\begin{array}{l}\text { Physical } \\
\text { Fumctioning }\end{array}$} & $B$ & -1.003 & -0.753 & 1.771 & -2.970 & -5.943 \\
\hline & $\bar{\beta}$ & -0.282 & $0-.055$ & 0.048 & $-0.104^{-}$ & 0.136 \\
\hline & Sig. & $0.000^{*}$ & 0.448 & 0.528 & 0.176 & 0.086 \\
\hline \multirow[t]{3}{*}{ Physical Role } & $B$ & -1.535 & -0.232 & $0.864^{-}$ & -8.065 & -5256 \\
\hline & $\bar{\beta}$ & -0.257 & $-0.010^{-}$ & 0.014 & -0.168 & -0.069 \\
\hline & Sig. & $0.001^{*}$ & 0.891 & 0.857 & $0.032:$ & 0.391 \\
\hline \multirow[t]{3}{*}{ Bodily Pain } & $B$ & -0.314 & 0.253 & -0.397 & -6.153 & -3.890 \\
\hline & $\bar{\beta}$ & -0.092 & 0.019 & $0-.011$ & -0.224 & -0.092 \\
\hline & Sig. & 0.248 & 0.799 & 0.888 & $0.005^{*}$ & 0.260 \\
\hline \multirow[t]{3}{*}{ General Health } & $B$ & -0.219 & -0.029 & 0.187 & -1.734 & -5.143 \\
\hline & $\bar{\beta}$ & -0.098 & -0.003 & 0.008 & -0.097 & -0.186 \\
\hline & Sig. & 0.221 & 0.964 & 0.919 & 0.230 & $0.025^{*}$ \\
\hline \multirow[t]{3}{*}{ Vitality } & $B$ & -0.705 & -0.821 & 5.003 & -5.521 & -10.716 \\
\hline & $\bar{\beta}$ & -0.168 & -0.051 & 0.114 & -0.164 & -0.207 \\
\hline & Sig. & $0.029^{-}$ & 0.484 & 0.133 & $0.034^{*}$ & $0.009 \div$ \\
\hline Social & $B$ & $-0.377^{-}$ & 1.004 & -2.909 & -3.369 & -3.332 \\
\hline \multirow[t]{2}{*}{ Functioning } & $\bar{\beta}$ & -0.131 & 0.091 & -0.097 & -0.146 & -0.094 \\
\hline & Sig. & 0.099 & 0.229 & 0.218 & 0.068 & 0.251 \\
\hline \multirow[t]{3}{*}{ Emotional Role } & $B$ & -0.697 & -0.489 & 3.322 & -5.124 & $-18.684^{-}$ \\
\hline & $\beta$ & -0.121 & -0.022 & 0.055 & -0.111 & -0.262 \\
\hline & Sig. & 0.119 & 0.764 & 0.472 & 0.156 & $0.001^{*}$ \\
\hline \multirow[t]{3}{*}{ Mental Health } & $\bar{B}$ & -0.877 & 0.674 & -2.448 & -3.496 & -11.192 \\
\hline & $\bar{\beta}$ & -0.264 & 0.053 & -0.071 & -0.132 & -0.274 \\
\hline & Sig. & $0.000^{*}$ & 0.445 & 0.328 & 074 & $0.000^{*}$ \\
\hline \multirow{3}{*}{$\begin{array}{l}\text { Health } \\
\text { Transition }\end{array}$} & $B$ & 0.715 & 0.329 & 2.879 & $-00.301^{-}$ & 3.292 \\
\hline & $\bar{\beta}$ & 0.225 & 0.027 & 0.087 & -0.012 & 0.084 \\
\hline & Sig. & $0.006^{-2}$ & 0.724 & 0.276 & 0.884 & 0.310 \\
\hline
\end{tabular}

Table 10

STANDARDIZED $(\beta)$, UNSTANDARDIZED (B) COEFFICIENTS AND THEIR SIGNIFICANCE FOR THE SECOND TESTED MODEL with other reported results [51,58]. In regard to SF-36, the subscale scores were similar to other literature reports, targeting hospitalized populations [59, 60]. The highest scores were, thus, obtained for the Physical Functioning subscale $(76.91)[59,60]$, followed by the General Health Perceptions, Energy/Fatigue and Social Functioning subscale scores. OHIP-49 subscales investigating the psychological and social impacts of oral disease, registered the smallest scores. In comparison, the SF-36 subscales, dealing with psychological and social outcomes of the general health state, similarly registered lower scores.

In regard to the overall DMFT average scores, normative survey data for Romania is scarce in the literature. Compared to a study conducted on an industrialized Romanian population, the current study obtained greater DMFT values, in similar age intervals [61]. For further comparison, other South-Eastern European regional reported surveys have been investigated (comparisons are presented in respect to the overall sample): in the current study, the mean average overall sample DMFT score value was greater than the one reported in a survey, conducted in a Croatian population [62]; a survey which took place in Hungary generated similar results for the average DMFT within the 18-45 age interval; however, beyond 45 years, the presentstudy's resulted DMFT values were higher [63]; a study conducted on a Bulgarian adult population [64] indicated higher decayed and filled teeth mean scores, compared to the present study, but a lower missing teeth average score; both the aforementioned study and the current study obtained greater scores for the missing teeth; in a study conducted in a Spanish population, high DMFT scores were obtained for the institutionalized elderly population, generating, thus, comparable results with the current study's similar age hospitalized patient segment [65]. Regarding the suggestions driven from the aforementioned studies, it can be concluded that the current study sample was characterized by a poor oral health status. A study, investigating the oral health of a non-institutionalized sample, obtained a similar DMFT average as the current study, for individuals over 65 years, offering further support for the poor oral health status of the current sample[66].

Firstly, the overall DMFT scores have been correlated with both age and education. The correlations were statistically significant; in respect to the education, higher levels of education were significantly associated with higher DMFT scores, and thus, with a more reduced level of oral health. The overall DMFT scores also presented a reduced significant correlation with the overall OHIP-49Ro scores.

Secondly, correlations have been computed between OHIP-49Ro subscale scores and age, as well as for the overall OHIP-49Ro score and age. Only the scores belonging to the Physical Disability scale have been statistically significant correlated to the sample's age. Moreover, correlations, between the SF-36 subscale scores and age, have been investigated. Six of the eight SF-36 subscale scores correlated statistically significant with age. The obtained correlations were negative. Thus, higher SF-36 subscale scores were associated with a younger age, older subjects reporting a poorer HRQOL. The greater number of correlations between age and the SF- 36 subscale scores, compared to the ones between age and OHIP-49Ro overall and subscale scores, reflect the fact that the interviewed patients tended to give more importance to the state of general health. Younger patients reported a better selfperceived state of general health.

In order to assess more complex interrelations between oral health clinical and self-perceived determinants and OHRQOL and also between OHRQ $\mathrm{L}$ and HRQoL, multiple linear regression has been applied, as follows:

1.A first set of regression models has been computed, having as predictors the DMFT overall score, global oral health self-perception question, the denture assessment question group, the assessment of para-functions question group and the assessment of oral discomfort question group. The dependent variables were represented by the OHIP-49 overall score and, separately, the seven OHIP-49 subscale scores. The purpose of this procedure was to investigate if objective factors (DMFT, denture condition) 
and a simple set of oral-health self-assessment questions, can impact a more complex oral health perception, defined as OHRQ oL (and represented by the overall OHIP-49 score). All the regression models were significant (Table 7). The predictors accounted for $48.5 \%$ of variance in OHRQoL, which is consistent with other literature studies [67]. In other studies, similar predictors managed to explain only a smaller percent of variance in the OHRQoL [33]. The global oral health self-perception question and the oral discomfort assessment questions group were the only predictors to statistically significantly explain the variance in the OHIP-49 overall scores, within the model. In respect to the regression models, having as dependent variable each OHIP-49 subscale, Functional Limitation, Physical Disability and Pain presented the highest variance, which was accounted by all the five predictors together. The DMFT overall score accounted significantly only for the variance in the Physical Disability subscale $(p=0.02)$. The denture assessment questions were not related to any of the seven OHIP-49 subscale scores. The self-awareness in respect to parafunctions (tooth grinding, interposing objects between the arches) accounted significantly only for the variance in Functional Limitation $(p=0.013)$ and Pain ( $p$ $=0.013$ ). The oral discomfort self-evaluation questions (burn syndrome, TMJ sounds or pain) were significantly related to Functional Limitation $(p=0.002)$, Pain $(p=$ $0.001)$, Physical Disability $(p=0.004)$ and Handicap $(p=0.013)$. Thus, a general pattern can be suggested, in which the patients tended to highlight mostly the impact of physical symptoms upon their own oral health perceptions. These impacts were however, not related to the denture status.

2.A second set of regression models has been computed, having as predictors: the DMFT overall score, the denture assessment questions, the questions regarding parafunctions, the questions evaluating oral discomfort and the OHIP overall score. The dependent variables were represented by the eight SF-36 subscale scores. The aim of the procedure was to assess if the OHRQ oL (represented by the overall OHIP-49Ro score combined with the other aforementioned predictors) has any effectupon the HRQoL of the patients (represented by the SF-36 subscale scores). All the regression models were significant (Table 9). Because, in concordance with the authors' guidelines, no SF-36 overall score is calculated [16], a regression model was computed for each of the eight SF-36 subscale scores. The highest percents of variance, explained by the predictors, was registered for the following subscales: Mental Health $(22.8 \%)$, Vitality $(15.4 \%)$, Physical Functioning (15.1\%), and Emotional Role (13.2\%). The predictors which accounted significantly, for the variance in these subscales, were: the overall DMFT score, the oral discomfort questions and the OHIP-49Ro overall score. The DMFT predicted significantly four of the eight SF-36 subscales: Physical Functioning, Physical Role, Vitality, Mental Health (Table 10), while the OHIP-49 overall score was statistically significantly related to the following SF36 subscales: General Health, Social Functioning, Mental Health (Table 10).

The DMFT score predicted more physical and functional related aspects of both OHRQOL and HRQ oL (The DMFT overall score being significantly related to subscales investigating physical aspects, for both SF-36 and OHIP49Ro questionnaires). Also, DMFT was a statistically significant predictor rather for a larger number of HRQOL dimensions, than for the OHRQoL dimensions. The OHIP49Ro overall score was related to the general health and social functioning aspects of HRQ oL. The relation between the OHIP-49Ro scores and the general health and social subscales of SF-36 can be explained by the large number of OHIP-49RO questions, addressing general health complication, due to oral pathology.

The OHIP-49 subscales, investigating psychological and social effects of the oral pathology, registered the lowest scores (Table 5 ). In comparison, the SF-36 subscales investigating psychological or emotional impacts, registered smaller score differences, in respect to the physical and functional subscales of SF-36. This might suggest, that, hospitalized internal medicine patients, tend to be focused on the negative impact of their current general pathology, due to which they underwent hospitalization. The interviewed patients also presented the tendency to rather focus upon the answers for the SF36 items (assessing HRQoL), in comparison to the ones for the OHIP-49Ro (assessing the OHRQoL). In respect to the OHIP-49Ro, the patients tended to emphasize the physical oral impacts, rather than the psychological impacts. Nonetheless, psychological impacts in respect to the general health were answered more carefully and in-depth. This phenomenon might explain the apparent good OHRQ oL, by the self-report of a poor oral health only among $30 \%$ of the patients.

In respect to the assessment of dentures, the existing denture types comprised acrylic removable complete dentures, acrylic removable partial dentures, metal fixed partial dentures, metal-acrylic fixed partial dentures and porcelain-fused-to-metal fixed partial dentures. The distribution of these denture types can be assessed in table 2. No full ceramic fixed denture was recorder in the current study, as well as no other removable denture material types. This fact can partially be explained by the relative high percent of elderly patients, living as retired individuals, with imited financial possibilities. Supplementary, all the involved subjects were patients within a public healthcare unit. Although only $5.89 \%$ presented more than 24 present teeth in the oral cavity, $40 \%$ of the patients were not denture wearers. The majority of the assessed dentures were in a used state $(88.2 \%)$, all the fixed metal-acrylic ones presenting color changes, surface texture modifications, and veneer chipping. Although in a used state, all investigated porcelain-fused-to-metal dentures were kept intact. In respect to the removable dentures, no pathological modifications were assessed at the denture materialmucosal interface. The presence of an artificial material within the oral cavity had no influence on the self-perceived OHRQOL, when compared to denture non-wearers. However, within the group of fixed denture wearers, the ones, presenting porcelain-fused-to metal dentures, reported the best OHRQoL, when compared both to fullmetal dentures wearers or metal-acrylic wearers. This fact can be correlated with the advantages provided by the porcelain-fused-to metal partial fixed dentures, in comparison to the full-metal or acrylic ones: higher biocompatibility, enhanced aesthetics, optical and surface properties, strength and considerably longer lifespan. The effect of the interaction between the presence of a denture and gender on OHRQOL was statistically significant only for the handicap subscale, female denture wearers presenting higher subscale scores, compared to men. It should be noted, though, that $76.19 \%$ of the porcelainfused-to metal wearers were females. No statistically significant effects were registered for the other OHIP-40Ro subscales or for the OHIP-49RO overall score, possibly indicated a reduced perceived impact exerted by an artificial material, within the oral cavity. 
The hypotheses, addressed in the current study, have been investigated, as well, in similar studies. OHRQoL has been related to poor mental health and psychical insecurity [68]. The sample in the current study presented a higher degree of awareness in general health related aspects, compared to the ones in oral health. Hospitalized samples presented as well, a lack of awareness in oral health, within other studies [69]. The current study aims to contribute to the results regarding the effect of denture materials upon the patients' OHRQoL. Hence, it is able to provide partial support that, denture materials, contribute, to some extent, to the perception of an improved or altered OHRQoL. This finding is in accordance to other literature findings (44).

\section{Conclusions}

In conclusion, determinants of oral health were partially related with the OHRQoL, within the current sample. However, OHRQoL was a good predictor for HRQoL, as an integrated part of it. The clinical determinants presented direct impact on both OHRQOL and HRQoL. Morele balanced HRQoL scores suggested that patients tended to focus more on the general health outcomes, while selfperceived oral health was secondary in importance. This is the first study in Romania, which applies the OHIP-49 in a hospitalized population, assessing the OHRQoL of the subjects. Given the fact, that the sample was represented by a convenience sample, the authors suggest the expanding of further studies on larger samples.

\section{References}

1. GELLERT GA. The importance of quality of life research for health care reform in the USA and the future of public health. Qual Life Res. 1993;2(5):357-61.

2. AHMED N, AHMED S, CARMICHAEL Z, SAMI AS. Measuring Healthy Lifestyle and Mental Health Indicators in South Asian Women Using the "Your Health: Quality of Life and Well-Being" Questionnaire. Ann Glob Health. 2017;83(3-4):463-70.

3. FELCE D, PERRY J., Quality of Life: Its Definition and Measurement. Res Dev Disabil. 1995;16(1):51-74.

4. MARCEL WM. Definitions of Quality of Life: What Has Happened and How to Move On. Top Spinal Cord Inj Rehabil. 2014;20(3):167-80. 5. MEERBERG GA. Quality of life: a concept analysis. J Adv Nurs. 1993;18(1):32-8.

6. BOWLING A, GABRIEL Z. An Integrational Model of Quality of Life in Older Age. Results from the ESRC/MRC HSRC Quality of Life Survey in Britain. Social Indicators Research. 2004;69(1):1-36.

7. BOWLING A, BANISTER D, SUTTON S, EVANS O, WINDSOR J. A multidimensional model of the quality of life in older age. Aging Ment Health. 2002;6(4):355-71.

8. GIFT HC, ATCHISON KA. Oral health, health, and health-related quality of life. Med Care. 1995;33(11 Suppl):NS57-77.

9. AIBAKER AM, AlBaqami FF, AlHarbi TM, AIAMRI MD, BASKARADOSS JK. Oral Health Status and Oral Health-related Quality of Life among Hospitalized and Nonhospitalized Geriatric Patients. J Contemp Dent Pract. 2017 18(3):228-34.

10. ZUCOLOTO ML, MAROCO J, Campos JADB. Impact of oral health on health-related quality of life: a cross-sectional study. BMC Oral Health. 2016;16(1):16:55.

11. JOHN MT, HUJ OEL P, MIGLIORETTI DL, LERESCHE L, KOEPSELL TD, MICHEELIS W. Dimensions of oral-health-related quality of life. J Dent Res. 2004;83(12):956-60.

12. J OHN MT, RENER-SITAR K, BABA K, CELEBIC A, LARSSON P, SZABO $G$, et al. Patterns of impaired oral health-related quality of life dimensions. J Oral Rehabil. 2016;43(7):519-27.

13. SISCHO L, BRODER HL. Oral health-related quality of life: what, why, how, and future implications. J Dent Res. 2011;90(11):1264-70.

14. GIFT HC, ATCHISON KA, DAYTON CM. Conceptualizing oral health and oral health-related quality of life. Soc Sci Med. 1997;44(5):601-8.
15. WARE JE, JR., SHERBOURNE CD. The MOS 36-item short-form health survey (SF-36). I. Conceptual framework and item selection. Med Care. 1992 30(6):473-83.

16. HAYES SP, SHERBOURNE CD, MAZEL RM. User's Manual for the Medical Outcomes Study (MOS) Core Measures of Health-Related Quality of Life. Santa Monica: RAND; 1994.

17. MARTINI A, AMMIRATI A, GARCIA C, ANDRADE C, PORTELA O, CENDOROGLO MS, et al. Evaluation of quality of life, physical, and mental aspects in longevous patients with chronic kidney disease. Int Urol Nephrol. 2018 Epub ahead of print.

18. RICOTTI S, MARTINELLI V, CASPANI P, MONTELEONE S, PETRUCCI $L$, DALLA TOFFOLA E, et al. Changes in quality of life and functional capacity after lung transplantation: A single-center experience. Monaldi Arch Chest Dis. 2017;87(3):831.

19. REN G, LUTZI, RAILTON P, WILEY J P, MCALLISTER J, POWELL J, et al. Serum and synovial fluid cytokine profiling in hip osteoarthritis: distinct from knee osteoarthritis and correlated with pain. BMC Musculoskeletal Disorders. 2018;19:39.

20. LOCKER D, MATEAR D, STEPHENS M, LAWRENCE H, PAYNE B. Comparison of the GOHAI and OHIP-14 as measures of the oral healthrelated quality of life of the elderly. Community Dent Oral Epidemiol. 2001;29(5):373-81.

21. ZUCOLOTO ML, MAROCO J, CAMPOSJA. Psychometric Properties of the Oral Health Impact Profile and New Methodological Approach. J Dent Res. 2014;93(7):645-50.

22. JOHN MT, REISSMANN DR, FEUERSTAHLER L, WALLER N, BABA $K$, LARSSON P, et al. Exploratory factor analysis of the Oral Health Impact Profile. J Oral Rehabil. 2014;41(9):635-43.

23. SLADE GD, SPENCER AJ. Development and evaluation of the Oral Health Impact Profile. Community Dent Health. 1994;11(1):3-11.

24. SLADE GD. Derivation and validation of a short-form oral health impact profile. Community Dent Oral Epidemiol. 1997;25(4):284-90.

25. BLAIZOT A, MONSARRAT P, CONSTANTIN A, VERGNES J N, DE GRADO GF, NABET C, et al. Oral health-related quality of life among outpatients with rheumatoid arthritis. Int Dent J. 2013 63(3):145-53.

26. SALAFFI F, CAROTTI M, GASPARINI S, INTORCIA M, GRASSI W. The health-related quality of life in rheumatoid arthritis, ankylosing spondylitis, and psoriatic arthritis: a comparison with a selected sample of healthy people. Health Qual Life Outcomes. 2009;7:25.

27. BARON M, HUDSON M, TATIBOUET S, STEELE R, LO E, GRAVEL S, et al. The Canadian systemic sclerosis oral health study: orofacial manifestations and oral health-related quality of life in systemic sclerosis compared with the general population. Rheumatology (Oxford). 201453 (8):1386-94.

28. BARON M, HUDSON M, TATIBOUET S, STEELE R, LO E, GRAVEL S, et al. The Canadian systemic sclerosis oral health study II: the relationship between oral and global health-related quality of life in systemic sclerosis. Rheumatology (Oxford). 2015 54(4):692-6.

29. SCHIMMEL M, LEEMANN B, CHRISTOU P, KILIARIDIS S, SCHNIDER A, HERRMANN FR, et al. Oral health-related quality of life in hospitalised stroke patients. Gerodontology. 2011 28(1):3-11.

30. MATHEWS MJ, MATHEWS EH, MATHEWS GE. Oral health and coronary heart disease. BMC Oral Health. 2016;16(1):122.

31. COATES EA, BRENNAN D, LOGAN RM, GOSS AN, SCOPACASA B, SPENCER AJ, et al. Hepatitis $C$ infection and associated oral health problems. Aust Dent J. 2000;45(2):108-14.

32. REI A, ROCHA M, PEDROTO I. Health-Related Quality of Life in Portuguese Patients with Chronic Hepatitis C. GE Port] Gastroenterol. 2017;24(2):68-78.

33. YU DS, LEE DT, HONG AW, LAU TY, LEUNG EM. Impact of oral health status on oral health-related quality of life in Chinese hospitalised geriatric patients. Qual Life Res. 2008;17(3):397-405.

34. POUSETTE LUNDGREN G, KARSTEN A, DAHLLOF G. Oral healthrelated quality of life before and after crown therapy in young patients with amelogenesis imperfecta. Health Qual Life Outcomes. 2015 13:197.

35. De KOK IJ, COOPER LF, GUCKES AD, MCGRAW K, WRIGHT RF, BARRERO C], et al. Factors Influencing Removable Partial Denture 
Patient-Reported Outcomes of Quality of Life and Satisfaction: A Systematic Review. J Prosthodont Res. 2017 26(1):5-18.

36. LOPEZ CAZAUX S, HYON I, PRUD'HOMME T, Dajean Trutaud S. Twenty-nine-month follow-up of a paediatric zirconia dental crown. BMJ Case Rep. 2017.

37. ESQUIVEL-UPSHAW JF, KIM MJ , HSU SM, ABDULHAMEED N, J ENKINS $R, N E A$ ID, et al. Randomized clinical study of wear of enamel antagonists against polished monolithic zirconia crowns. J Dent. 2018 68:19-27.

38. FABIAN FONZAR R, CARRABBA M, SEDDA M, FERRARI M, GORACCI C, VICHI A. Flexural resistance of heat-pressed and CAD-CAM lithium disilicate with different translucencies. Dent Mater. 2017;33(1):63-70. 39. WITTNEBEN JG, GAVRIC J, BELSER UC, BORNSTEIN MM, JODA T, CHAPPUIS V, et al. Esthetic and Clinical Performance of ImplantSupported All-Ceramic Crowns Made with Prefabricated or CAD/CAM Zirconia Abutments: A Randomized, Multicenter Clinical Trial. J Dent Res. 2017 96(2):163-70.

40. BOX VH, SUKOTJ O C, KNOERNSCHILD KL, CAMPBELL SD, AFSHARI FS. Patient-Reported and Clinical Outcomes of Implant-Supported Fixed Complete Dental Prostheses: A Comparison of Metal-Acrylic, Milled Zirconia, and Retrievable Crown Prostheses. J Oral Implantol. 2018 44(1):51-61.

41. CAMPBELL SD, COOPER L, CRADDOCK H, HYDE TP, NATTRESS B, PAVITT SH, et al. Removable partial dentures: The clinical need for innovation. J Prosthet Dent. 2017;118(3):273-80.

42. GENDREAU L, LOEWY ZG. Epidemiology and etiology of denture stomatitis. J Prosthodont. 2011 20(4):251-60.

43. YEN YY, LEE HE, WU YM, LAN SJ, WANG WC, DU JK, et al. Impact of removable dentures on oral health-related quality of life among elderly adults in Taiwan. BMC Oral Health. 2015;15(1).

44. TORRES ACSP, MACIEL AQ, DE FARIAS DB, DE MEDEIROS AKB, VIEIRA FPTV, CARREIRO ADFP. Technical Quality of Complete Dentures: Influence on Masticatory Efficiency and Quality of Life. J Prosthodont. 2019;28(1):e21-e6.

45. LOCKER D. Measuring oral health: a conceptual framework. Community Dent Health. 1988;5(1):3-18.

46. YULE PL, DURHAM J, PLAYFORD H, MOUFTI MA, STEELE J, STEEN $\mathrm{N}$, et al. OHIP-TMDs: a patient-reported outcome measure for temporomandibular disorders. Community Dent Oral Epidemiol. 2015 43(5):461-70.

47. BRODER HL, MCGRATH C, CISNEROS GJ. Questionnaire development: face validity and item impact testing of the Child Oral Health Impact Profile. Community Dent Oral Epidemiol. 2007 35(Suppl 1):8-19.

48. JOHN MT, PATRICK DL, SLADE GD. The German version of the Oral Health Impact Profile-translation and psychometric properties. Eur J Oral Sci. 2002;110(6):425-33.

49. Van der MEULEN MJ, JOHN MT, NAEIJE M, LOBBEZOO F. The Dutch version of the Oral Health Impact Profile (OHIP-NL): Translation, reliability and construct validity. BMC Oral Health. 2008:8:11.

50. WONG MCM, LO ECM, MCMILLAN AS. Validation of a Chinese version of the Oral Health Impact Profile (OHIP). Community Dent Oral Epidemiol. 2002 30(6):423-30.

51. SLADE GD. MEASURING ORAL HEALTH AND QUALITY OF LIFE. CHAPEL HILL, CA: University of North Carolina, Department of Dental Ecology; 1997.
52. ALLEN PF MA, LOCKER D. . An assessment of sensitivity to change of the Oral Health Impact Profile in a clinical trial. Community Dent Oral Epidemiol. 2001;29(3):175-82.

53. GRECU AG, DUDEA D, BALAZSI R, DUMITRASCU DL. Romanian version of the oral health impact profile-49 questionnaire: validation and preliminary assessment of the psychometrical properties. Clujul Med. 2015;88(4):530-6.

54. KLEIN H, PALMER C. Studies on dental caries vs. familial resemblance in the caries experience of sibling. Public Health Rep. 1938:53:1353-64.

55. *** ORGANISATION WH. Oral Health Surveys. Basic Methods. 5 ed. Geneva: World Health Organisation; 2013.

56. GEEVARGHESE A, BASKARADOSSJK, SARMA PS. Oral Health-Related Quality of Life and Periodontal Status of Pregnant Women. Matern Child Health J. 2017;21(8):1634-42.

57. ***IBM Corp. Released 2015. IBM SPSS Statistics for Windows, Version 22.0 [Computer Program]. Armonk, NY: IBM Corp.

58. YUEN HK, NELSON SL. Test-retest reliability of Oral Health Impact Profile (OHIP-49) in adults with systemic sclerosis. Spec Care Dentist. 2014;34(1):27-33.

59. BORTOLUZZI MC, de CAMARGO SMOLAREK P, CLAUDINO M, CAMPAGNOLI EB, MANFRO R. Impact of Dentofacial Deformity on Quality of Life: Age and Gender Differences Evaluated Through OQLQ, OHIP and SF36. J Oral Maxillofac Res. 2015 6(3):e3.

60. NAIMI AJ, NADERIRAVESH N, BAYAT ZS, SHAKERI N, MATBOUEI M. Correlation between health literacy and health-related quality of life in patients with hypertension, in Tehran, Iran, 2015-2016. Electron Physician. 2017;9(11):5712-20.

61. PETERSEN PE, TANASE M. Oral health status of an industrial population in Romania. Int Dent J. 1997(47):4.

62. RADIC M, BENJAK T, DECKOVIC VUKRES V, ROTIM Z, FILIPOVIC ZORE I. Presentation of DMFT/dmft Index in Croatia and Europe. Acta Stomatol Croa. 2015;49(4):275-84.

63. MADLENA M, HERMANN P, JAHN M, FEJ ERDY P. Caries prevalence and tooth loss in Hungarian adult population: results of a national survey. BMC Public Health. 2008;8(364).

64. DAMYANOV ND, WITTER DJ, BRONKHORST EB, CREUGERS HJ. Dental Status and Associated Factors in a Dentate Adult Population in Bulgaria: A Cross-Sectional Survey. Int J Dent. 2012:11.

65. EUSTAQUIO MV, MONTIEL JM, ALMERICH JM. Oral health survey of the adult population of the Valencia region (Spain). Med Oral Patol Oral Cir Bucal. 2010

15(3):538-44.

66. ESMERIZCE, MENEGHIM MC, AMBROSANO GM. Self-perception of oral health in non-institutionalised elderly of Piracicaba city, Brazil. Gerodontology. 2012;29(2):e281-9.

67. LLEWELLYN CD, WARNAKULASURIYA S. The impact of stomatological disease on oral health-related quality of life. Eur J Oral Sci. 2003;111(4):297-304.

68. JENSEN PM, SAUNDERS RL, THIERER T, FRIEDMAN B. Factors associated with oral health-related quality of life in communitydwelling elderly persons with disabilities. J Am Geriatr Soc. 2008 56(4):711-7.

69. SANCHEZ P, EVERETT B, SALAMONSON Y, AJWANI S, BHOLE S, BISHOP J, et al. Oral health and cardiovascular care: Perceptions of people with cardiovascular disease. PLoS One. 2017;12(7):e0181189.

Manuscript received: 9.05 .2019 